\title{
Vibrio parahaemolyticus: The Protagonist Causing Foodborne Diseases
}

\author{
Vengadesh Letchumanan ${ }^{1 *}$, Ke-Yan Loo ${ }^{1,2}$, Jodi Woan-Fei Law ${ }^{1}$, Sunny Hei Wong ${ }^{3}$, Bey-Hing Goh ${ }^{2}$, \\ Nurul-Syakima Ab Mutalib ${ }^{4}$, Learn-Han Lee ${ }^{1^{*}}$ \\ ${ }^{1}$ Novel Bacteria and Drug Discovery Research Group (NDBB), Microbiome and Bioresource Research Strength, Jeffrey \\ Cheah School of Medicine and Health Sciences, Monash University Malaysia, 47500 Bandar Sunway, Selangor Darul Ehsan, \\ Malaysia \\ ${ }^{2}$ Biofunctional Molecule Exploratory Research Group (BMEX), School of Pharmacy, Monash University Malaysia, 47500 \\ Bandar Sunway, Selangor Darul Ehsan, Malaysia \\ ${ }^{3} \mathrm{Li}$ Ka Shing Institute of Health Sciences, Department of Medicine and Therapeutics, The Chinese University of Hong Kong, \\ Shatin, Hong Kong \\ ${ }^{4}$ UKM Medical Molecular Biology Institute (UMBI), UKM Medical Centre, Universiti Kebangsaan Malaysia, Kuala Lum- \\ pur, Malaysia
}

\begin{abstract}
Food contamination is a worrying condition faced by us today. We often discuss on food safety and how to control food contamination. Food products are easily tainted by bacteria at any level of food production to human consumption, subsequently developing gastroenteritis. The people from developed and developing countries are at high risk from harmful effects of unsafe food. Of all the foodborne pathogens, Vibrio parahaemolyticus has been accounted for many outbreaks globally and still at rise even with proper management methods. V. parahaemolyticus infection occurs as a result of improper food handling and preparation, ability of the bacterium to withstand human gut to launch virulence, antibiotic resistant bacterium, and failure of regulatory bodies to safe-guard food quality. This scenario poses a global health issue that warrants rapid control measures to ensure food safety from production to consumption by consumers. For that reason, this review aims to provide an overview of the epidemiology of $V$. parahaemolyticus as well as discuss the challenges faced to encounter this bacterium.
\end{abstract}

Keywords: Food safety; contamination; foodborne; Vibrio parahaemolyticus; epidemiology

*Correspondence to: Learn-Han Lee; Jeffrey Cheah School of Medicine and Health Sciences, Monash University Malaysia, 47500 Bandar Sunway, Selangor Darul Ehsan, Malaysia. Email: lee.learn.han@monash.edu; leelearnhan@yahoo.com. Vengadesh Letchumanan; Jeffrey Cheah School of Medicine and Health Sciences, Monash University Malaysia, 47500 Bandar Sunway,

Received: $18^{\text {th }}$ May 2019

Accepted: $30^{\text {th }}$ June 2019

Published Online: 02 $2^{\text {nd }}$ July 2019 Selangor Darul Ehsan, Malaysia. Email: lvengadesh@ yahoo.com.

Citation: Letchumanan V, Loo KY, Law JWF, et al. Vibrio parahaemolyticus: The Protagonist Causing Foodborne Diseases. Prog Microbes Mol Biol 2019; 2(1): a0000029.

\section{INTRODUCTION}

FOOD is an essential part of every individuals for survival. It provide us with all the energy and nutrients for our healthy and active life. However, many of us ponder on one matter - How safe is our food? The World Health Organization (WHO) claimed that food is unsafe as it contains harmful bacteria, viruses, parasites or chemical substance, causing various illness ranging from diarrhea to cancers. It is estimated that 1 in 10 people in the world fall ill after consumption of contaminated food and lead to 420,000 die each year ${ }^{[1,2,3]}$. Food products are likely to be contaminated at any stages from production, processing, distribution, storage and preparation. These unsafe food poses a global health threat, increase hospitalization and healthcare cost, and constrains the national's economic development. Numerous studies revealed that marine and estuarine environments are the ecological niche of many bacteria. Undeniably, these bacteria are often encountered by consumers through seafood products, including Salmonella sp. ${ }^{[4-9]}$, Vibrio sp. ${ }^{[10,11,12,13,14]}$, Listeria monocytogenes ${ }^{[15,16]}$, and Escherichia coli, presented with foodborne outbreaks, pathogenicity, and clinical manifestations. Despite the good benefits of seafood, health hazards associated to seafood consumption cannot be ignored ${ }^{[17]}$. 
Vibrio species are common foodborne pathogen group that's accounted for human gastroenteritis cases worldwide; the most human pathogenic species are Vibrio cholerae, Vibrio parahaemolyticus and Vibrio vulnificus ${ }^{[14]}$. This Gram-negative rod-shaped bacterium is a natural constituents of marine and estuarine environments, and often been associated with seafood ${ }^{[18]}$. The non-cholera Vibrio sp., Vibrio parahaemolyticus, causes vibriosis and readily isolated from seafood including shellfish, oysters, shrimps, cockles, and fish ${ }^{[11,12,19]}$. The outbreaks of $V$. parahaemolyticus are becoming increasingly common in developed and non-developed countries such as Asia region, United States, Europe, Australia, and other nations ${ }^{[10]}$. According to data published by Centers for Disease Control and Prevention (CDC) in Foodborne Diseases Active Surveillance Network (FoodNet), and Morbidity and Mortality Weekly Report (MMWR), $V$. parahaemolyticus has accounted for approximately 34,664 incidents of domestically developed foodborne infection cases and known as the leading bacterium unlike to other Vibrio sp. in the United States (US) in $2016^{[20,21]}$. The consumption of contaminated food, undercooked or raw seafood leads to $V$. parahaemolyticus gastroenteritis with manifestation of watery diarrhea, stomach pains, nausea, and fever ${ }^{[22]}$. In rare cases, infections of $V$. parahaemolyticus can cause septicemia leading to an increase in number of fatality cases ${ }^{[23]}$. By taking into consideration of past reports and possibility of severe infections, this review aims to provide an overview of the epidemiology of $V$. parahaemolyticus as well as the rising challenges faced to curb this bacterium.

\section{HISTORY OF Vibrio and Vibrio parahaemolyti-} cus

Vibrio genus was first described by an Italian physician, Filippo Pacini in 1854. He discovered the first Vibrio species, Vibrio cholera, the causative agent of cholera while studying outbreaks of cholera disease in Florence $^{[24]}$. Subsequently, this strain was renamed as Vibrio cholerae, which is now the type of species of the genus. He further pointed out that cholerae is contagious but his discovery on Vibrio was ignored by the scientific community around the world ${ }^{[24]}$. After nearly 30 years, Robert Koch successfully isolated Vibrio from pure culture in Calcutta, India. At that time Vibrio epidemic was very active in Calcutta, India. Koch's discovery had created an important social consequence and regarded as a public health triumph ${ }^{[25]}$. Vibrio genus consist of 142 species that are marine originated and its taxonomy is continuously been revised due to the discovery and inclusion of new species ${ }^{[26]}$. Vibrio sp. infects any living being including animals and humans ${ }^{[27]}$. It was reported that a few of the species from this genus have been identified and classified among the top 15 pathogens causing nearly $95 \%$ of the foodborne diseases, hospitalizations and even deaths in the United States ${ }^{[28]}$. Recently, the worldwide ocean warming and climate changes have caused emerges of Vibrio sp. including the foodborne pathogenic strains with several virulence factors in marine environments.

As a member of the Vibrionaceace family and Vibrio genus, Vibrio parahaemolyticus has been in limelight for the rising vibriosis and foodborne cases worldwide. $V$. parahaemolyticus was first identified in 1951 by Tsunesaburi Fujino from Research Institute of Microbial Diseases (RIMD), Osaka University from an acute gastroenteritis outbreak. The outbreak occurred in a southern suburb of Osaka, Japan due to consumption of 'shirasu', a type of dried sardine which resulted in 20 deaths and 272 infected patients ${ }^{[29,30]}$. After several bacteriological testing and analysis, Fujino noticed that the strain exhibited hemolytic activity on blood agar and named the strain as Pasteurella parahaemolytica, assigning it to genus Pasteurella. The progression in taxonomy and various scientific discoveries led to the re-examination of Pasteurella parahaemolytica by Fujino. He reported that the genus of the isolate should be Vibrio instead of Pasteurella. In 1963, Sakazaki investigated Fujino's isolates and confirmed it was the same species belonging to Vibrio genus and propose to name the isolate as Vibrio parahaemolyticus ${ }^{[30]}$.

\section{EPIDEMIOLOGY OF Vibrio parahaemolyticus}

Vibrio parahaemolyticus is largely present in the aquatic environments and often isolated from seafood ${ }^{[31]}$. Since its discovery in 1950, V. parahaemolyticus has caused many foodborne outbreaks around the world including in Ja$\operatorname{pan}^{[32-36]}$, in Taiwan ${ }^{[37]}$, in China since early $1990 \mathrm{~s}^{[38]}$, Bangladesh $^{[39]}$, Laos ${ }^{[40]}$, Hong Kong and Indonesia ${ }^{[40]}$ (Figure 1). Despite the advances in hygiene and food processing, this foodborne pathogen still represents a significant threat to human health worldwide.

\section{Asia}

Vibrio parahaemolyticus was initially identified as a seafood-associated disease in the Eastern Asia region. This bacterium was first isolated in 1951 from a foodborne outbreak in Osaka, Japan due to consumption of shirasu, which resulted in 272 infected patients and 20 deaths ${ }^{[29,30]}$. Since then, many $V$. parahaemolyticus gastrointestinal cases have been reported in around Japan are due to the habit of eating raw or undercooked seafood such as sushi, sashimi, shellfish, crabmeat, fish, squid and sea urchin ${ }^{[41,42]}$. There was an increasing trend of reported cases from 1993 (837 cases) to 1998 (12, 318 cases), nevertheless the figures drastically dropped to 14 cases in 1999 and 280 cases in $2009^{[42]}$. The decrease in number of $V$. parahaemolyticus foodborne cases from 1999-2000 is due to the implementation of regulatory actions to improve the hygiene conditions in all seafood production sites in Japan ${ }^{[35]}$. Even with appropriate regulatory measures, there are still many reported $V$. parahaemolyticus cases in Japan.

In the neighboring nation China, $V$. parahaemolyticus was identified as a major cause of foodborne disease since early 1990s. Seafood such as crustaceans was the vehicle for V. parahaemolyticus to transmit vibriosis infection in Chi$\mathrm{na}^{[43]}$. From 1991-2001, a total of 5770 foodborne cases was reported, which $31 \%$ of them was caused by $V$. parahaemolyticus $^{[44]}$. The number of outbreaks decline to 322 cases between 2003 and 2008 ${ }^{[43]}$. Li and colleagues found that $V$. parahaemolyticus was the main cause of acute diarrhea during 2007-2012 in southern coastal region of China, with the most prevalent serotype O3:K6 followed by $\mathrm{O} 4: \mathrm{K} 8$ and $\mathrm{O} 3: \mathrm{K} 29^{[37]}$. In Taiwan, many foodborne gastroenteritis outbreaks were identified to be caused by V. parahaemolyticus ${ }^{[32,37,45]}$. 


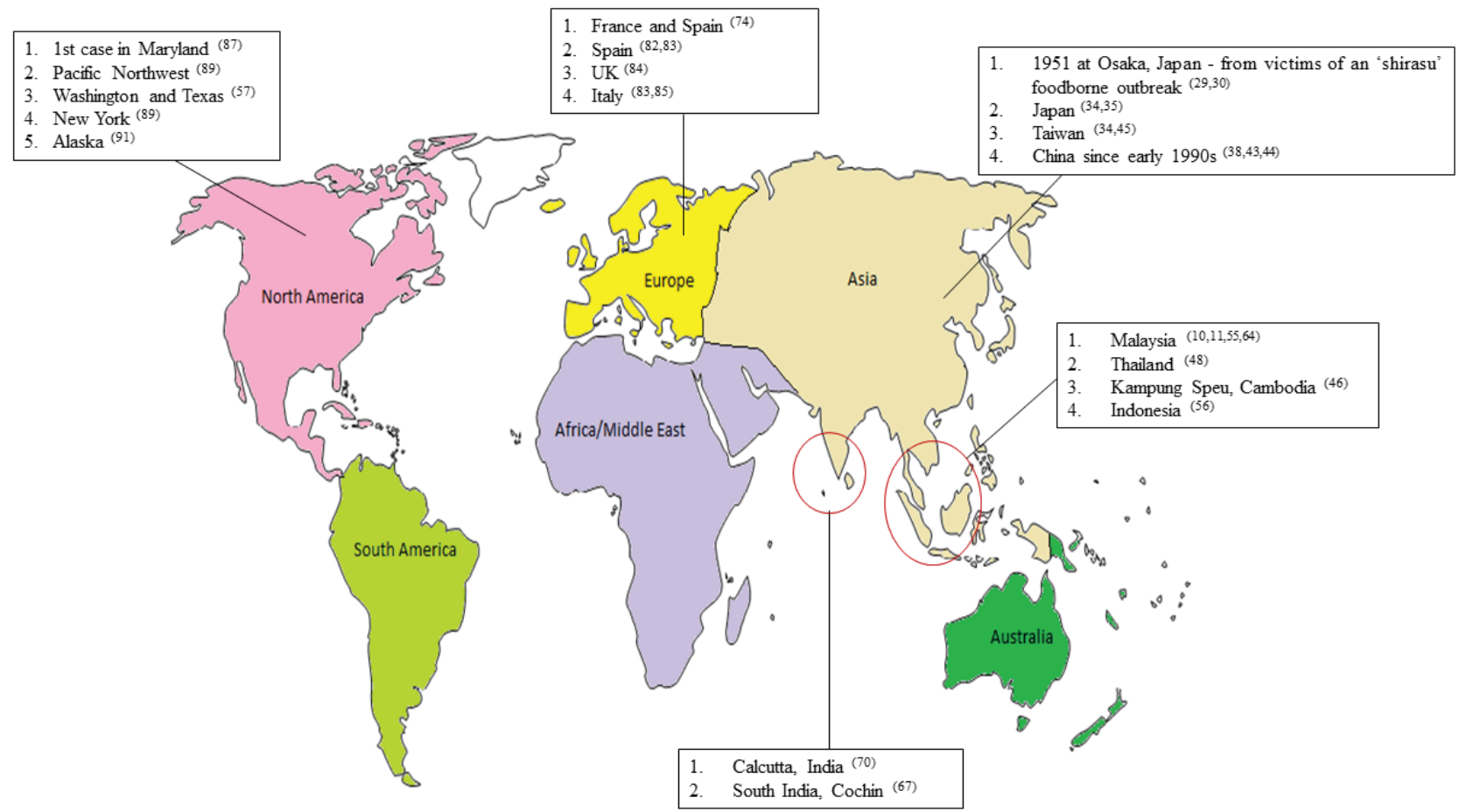

Figure 1: Illustration of $V$. parahaemolyticus epidemiology around the world. The first identified case was in Osaka, Japan in 1951 and ever since then the occurrence has spread to whole of Asia region, Australia, Europe, and the United States (US).

In Southeast Asia regions - Laos, Thailand, Indonesia and Cambodia, V. parahaemolyticus was accounted for several foodborne outbreaks ${ }^{[46]}$. V. parahaemolyticus first outbreak occurred in Kampung Speu, Cambodia resulted in 49 cases of acute diarrhea ${ }^{[47]}$. In Thailand, the pandemic O3:K6 serotype strains was accountable for most of the foodborne cases between 2006 and $2010^{[48]}$. Thailand is known as the main producer and exporter of cultured shrimp to around the global. This industry is on alert due the occurrence of antimicrobial resistant $V$. parahaemolyticus isolated from white leg shrimp and black leg shrimp from inland ponds ${ }^{[49]}$.

In Malaysia, $V$. parahaemolyticus occurs naturally in the marine and coastal regions. It spreads in the tropical marine surroundings during all seasons and causes foodborne gastroenteritis $^{[50]}$. In the early $1980 \mathrm{~s}$, a study revealed the detection of $V$. parahaemolyticus in Malaysian shrimp. It is of interest to note that 21 different serotypes were isolated from Malaysian shrimp, with type 01:K38 and 01:K32 were predominated ${ }^{[51]}$. In 2005, a study reported the isolation of $V$. parahaemolyticus from cockles (Anadara grano$s a$ ) at a harvesting area at Tanjong Karang, Kuala Selangor. The analysis revealed virulent $V$. parahaemolyticus isolates having the thermostable direct hemolysin $(t d h)$ and TDHrelated hemolysin (trh) genes ${ }^{[52]}$. Virulent $V$. parahaemolyticus carrying $t d h$ genes and trh genes was also identified from frozen shrimp in Malaysia, prompting a possible health risk for people consuming raw shrimp ${ }^{[53]}$. In 2011, a study reported high occurrence of Vibrio sp. (98.6\%) and $V$. parahaemolyticus $(24 \%)$ in freshwater fish collected from hypermarket. This outcome indicates a potential source of unsafe food to consumers in Malaysia ${ }^{[54]}$. In addition, recently there was report about European Union (EU] countries rejected frozen black tiger shrimp from Malaysia due to the presences of $V$. parahaemolyticus and this further affected the Malaysian economic ${ }^{[55]}$.

Paydar and colleagues reported prevalence of $V$. para- haemolyticus in the seafood samples from retail and hypermarkets in Malaysia. Out of the 43/150 V. parahaemolyticus isolates detected, six isolates carried the trh genes and another two carried the $t d h$ genes $^{[55]}$. Recently, a comparative study was done to detect the contamination level of $V$. parahaemolyticus in seafood marketed in Thailand, Vietnam, Malaysia, and Indonesia. Interestingly, the study's results revealed that all the four countries had a similar levels of $V$. parahaemolyticus contamination in fish, shrimp, squid, crab, and shellfish. The study did not detect any virulent strains among the seafood samples from Malaysia ${ }^{[56]}$. The findings in agreement with other reports globally that mentioned virulent genes, the $t d h$ and $t r h$ are very low number (1$7 \%$ ) among environmental and seafood samples ${ }^{[57-61]}$.

The food safety levels in Malaysia further declined due to the prevalence of antibiotic resistant $V$. parahaemolyticus isolated from seafood ${ }^{[11,12,62]}$. In Terengganu, Malaysia, a study reported the detection of cefuroxime and ceftazidime-resistant $V$. parahaemolyticus isolates in shellfish samples ${ }^{[62]}$. In addition, ampicillin resistant profiles are often detected among seafood samples in Malaysia ${ }^{[11,50,63,64,65]}$. Elexson and colleagues reported in their study that all of the $V$. parahaemolyticus isolates from cultured seafood products were resistant to both penicillin and ampicillin ${ }^{[63]}$. In a recent study, high level of penicillin and ampicillin resistant isolates were obtained from short mackerels in Malaysia ${ }^{[66]}$. The ampicillin resistance seen may be due to misappropriation of the first-generation antibiotic for pathogen management in aquaculture, thus reducing the efficacy of ampicillin in the treatment of Vibrio infection ${ }^{[67]}$. Hence, it is indeed vital to address and manage the antimicrobial resistance issue.

In India, $V$. parahaemolyticus was detected and identified from both clinical and environmental samples. The first serotype O3:K6 $V$. parahaemolyticus was discov- 
ered in an on-going surveillance in Calcutta, India ${ }^{[68-70]}$. Subsequently, the serotype $\mathrm{O} 3: \mathrm{K} 6 \mathrm{~V}$. parahaemolyticus has turned into a widespread around Asia. In a clinical study, $178 \mathrm{~V}$. parahaemolyticus strains was isolated from 13,607 diarrheal patients admitted in Infectious Diseases Hospital, Kolkata since 2001 to $2012^{[71]}$. V. parahaemolyticus diarrheal cases were also detected from around the urban slums of Kolkata, India ${ }^{[72]}$. Reyhanath and colleagues have reported detection and isolation of antimicrobial resistant V. parahaemolyticus strains from a fishing land in South India $^{[72]}$. In Cochin, a study reported the isolation of Vibrio sp. including pathogenic and antimicrobial resistant $V$. parahaemolyticus strains from seafood. Most of the isolates was seen resistant to ampicillin and multidrug resistance was prevalent among the isolates ${ }^{[73]}$. The prevalence of multidrug resistant $V$. parahaemolyticus isolates in environment and clinical setting is of public health concern, thus require continuous monitoring and management.

\section{Europe}

In European countries, $V$. parahaemolyticus infections are seldom reported, unlike Asia and US countries where $V$. parahaemolyticus infections are commonly reported ${ }^{[74]}$. However, there were several sporadic outbreaks reported over the last 20 years in countries such as France and $\mathrm{Spain}^{[32,74]}$. V. parahaemolyticus was isolated from the Baltic Sea, the North Sea, the Mediterranean Sea ${ }^{[75]}$, and Black $\mathrm{Sea}^{[76]}$. In 1978, studies were conducted in coastal waters of Guadeloupe and isolated $V$. parahaemolyticus from 53/100 water samples that was investigated ${ }^{[77]}$. Over the years, many cases of $V$. parahaemolyticus gastroenteritis were detected and isolated in Spain, Greece, Britain, Turkey, Denmark, Yugoslavia, the Scandinavian areas, and Italy ${ }^{[78,79]}$.

In $1989, V$. parahaemolyticus was accounted for 8 acute gastroenteritis cases linked with intake of fish and shellfish in Spain ${ }^{[80]}$. In 1997, a major outbreak of $V$. parahaemolyticus involving 44 patients had occurred in France and it was associated with the consumption of shrimps imported from $\mathrm{Asia}^{[81]}$. In 1999, the first large outbreak of $V$. parahaemolyticus occurred in Galicia, Spain. This outbreak involved 64 illnesses and it was associated with consumption of raw oysters ${ }^{[82]}$. A more recent outbreak of $V$. parahaemolyticus was reported in Spain in 2004, whereby it involved 80 illnesses among the guests who attended weddings in a restaurant. The investigation revealed that the outbreak was caused by consumption of boiled crab prepared under unsanitary conditions ${ }^{[83]}$. In 2004-2005, only 57 cases of $V$. parahaemolyticus infections was reported in United Kingdom and most of the infections were obtained through travel to endemic areas ${ }^{[84]}$. In addition, serotype 03:K6 $V$. parahaemolyticus strains were isolated from patients of outbreak in Spain and patients of gastrointestinal infection in Italy ${ }^{[83,85,86]}$.

\section{United States (US)}

In 1971, V. parahaemolyticus was first identified as an etiological food borne pathogen in Maryland, US after three outbreaks of 425 gastroenteritis cases associated with consumption of improperly cooked crabs $^{[87]}$. Ever since then, intermittent $V$. parahemolyticus outbreaks have been reported throughout the US coastal regions due to the consumption of raw shellfish or uncooked seafood. In 1973 to 1998 , a total of 40 outbreaks of $V$. parahaemolyticus infection was reported by the $\mathrm{CDC}^{[88]}$. Four out of 40 outbreaks involved over 700 cases of diseases linked with consumption of raw oyster in the Gulf Coast, Pacific Northwest, and Atlantic Northeast regions between the years 1997 to 1998. In 1997 summer, 209 (including one death) of $V$. parahaemolyticus infection cases was reported involving consumption of raw oyster in around the Pacific Northwest (Oregon, Washington, California and British Columbia of Canada) ${ }^{[89]}$. In 1998, there were two separate reports on $V$. parahaemolyticus infection cases in Washington (43 cases) and Texas (416 cases) ${ }^{[90]}$. In between July to September 1998, there was eight $V$. parahaemolyticus infection cases reported in around Connecticut, New Jersey, and New York as a result of eating oysters and clams harvested from Long Island Sound of New York ${ }^{[89]}$.

In summer 2004, 14 passengers on a cruise ship in Alaska experienced gastroenteritis symptoms after ingestion raw oysters produced in Alaska ${ }^{[91]}$. The O6:K18 isolates from the Alaska outbreak were in differentiated by PFGE from those isolated in the sporadic cases from Pacific Coast states over the previous decade. From July to October of 2004, 96 ecological samples were collected from 17 Alaska oyster farms, and $32 \%$ of the samples were $V$. parahaemolyticus with the prevalent serotypes of $\mathrm{O} 1: \mathrm{K} 9, \mathrm{O} 4: \mathrm{K} 63$, and $\mathrm{O} 6: \mathrm{K} 18^{[92]}$. In summer 2006, there was an outbreak involving 177 gastroenteritis cases resulted from ingestion of oysters contaminated with $V$. parahaemolyticus in Washington and British Columbia $^{[93]}$. In summary, the prevalence of $V$. parahaemolyticus in both clinical and environmental samples potentially rises a serious food safety concern in the US.

\section{MAJOR CHALLENGERS OF Vibrio parahae- molyticus}

The regulatory bodies and healthcare sector is continuously challenged by increasing numbers of antibiotic resistant $V$. parahaemolyticus strains in the environments. The occurrence of multidrug-resistant (MDR) towards clinically used antibiotics is a major health issue and deprives the global drug discovery programs ${ }^{[94]}$. Each year, more and more pathogenic Vibrio sp. have been reported to develop resistance towards most of the clinically used antibiotics (Figure 2). Drug resistance is an alarming issue worldwide and is spreading rapidly due to overuse, self-medication or the non-therapeutic use of antimicrobials $^{[95]}$. The countries around the world have reported the detection of MDR $V$. parahaemolyticus in seafood, prompting the need for continuous surveillance and monitoring in the aquaculture industry ${ }^{[96-99]}$.

It is reported that over $90 \%$ of the marine originated bacteria isolates display resistance towards more than one type of antibiotic. In addition, 20\% of them exhibited resistance towards five types of antibiotics ${ }^{[100]}$. The marine environments are more prone to antibiotics and antibiotic resistant genes due to the misuse of antibiotic agents in hospital or veterinary treatment, aquaculture and agriculture locations, and their successive release into wastewater treatment plant ${ }^{[101]}$. The elevated levels of antibiotic agents in the aquatic could play a role as a 


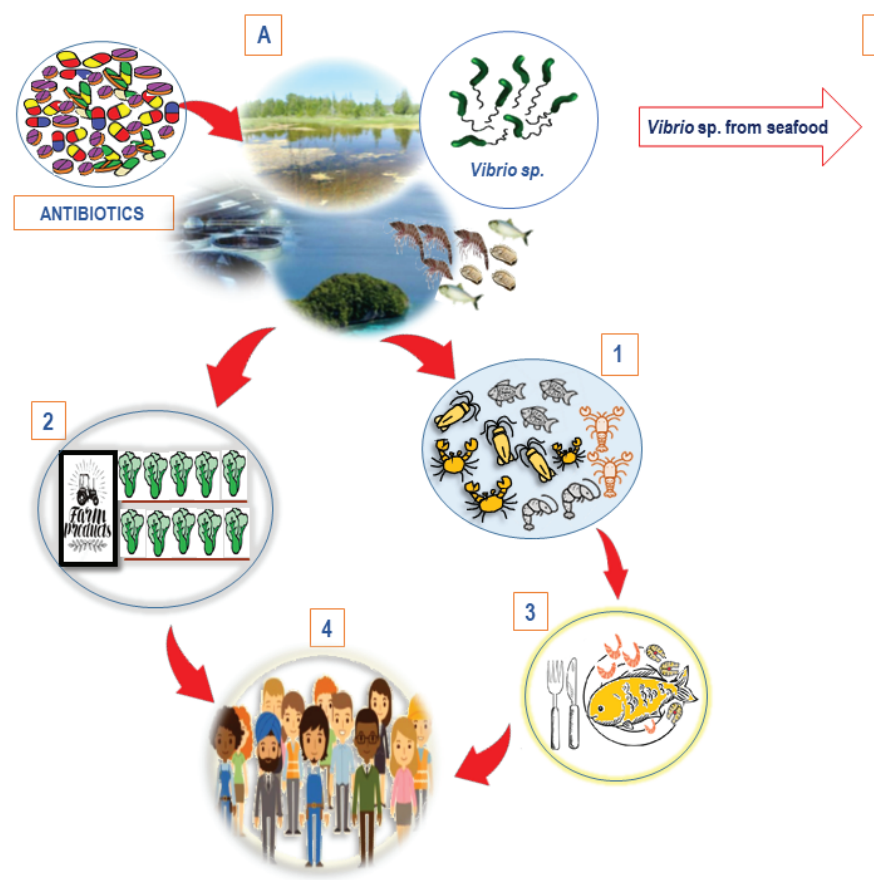

B
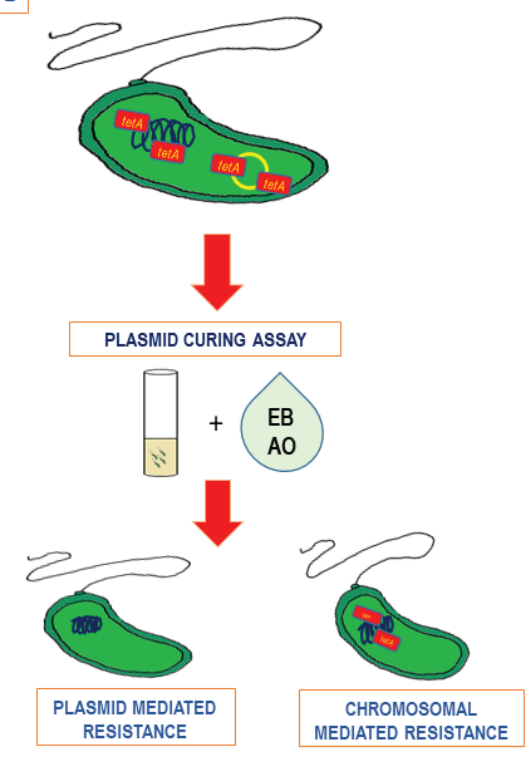

Figure 2: Illustration of Vibrio parahaemolyticus transmission to humans and plasmid curing assay. (A) Vibrio parahaemolyticus is found in the marine, estuarine, and aquaculture settings. Antibiotics are incorporated in feed and water to control Vibrio parahaemolyticus infections on aquatic animals such as shrimp, cockles, fish, and shellfish. This bacterium eventually develops antibiotic resistance and carries the resistance genes in them. 1) Vibrio parahaemolyticus uses seafood as a vehicle to transmit the carries the antibiotic resistance and resistant genes. 2) The antibiotics resides in water and transmitted to agriculture area thru irrigation. 3) Undercooked and raw seafood potentially carry pathogenic Vibrio parahaemolyticus and resistant strains. 4) Consumers will eat contaminated seafood and vegetable, thus exposing themselves to gastroenteritis. (B) Vibrio parahaemolyticus is isolated from seafood. Antibiotic susceptibility test is performed to determine the resistance profile. The antibiotic resistance could be either in the plasmid or chromosomal of the bacterium. The strain would be subject to plasmid curing assay to determine the antibiotic resistance mediation. Intercalating agents such as ethidium bromide or acridine orange can be used to cure the bacteria plasmid. After the assay, antibiotic resistance mediation could be determine either it is plasmidial or chromosomal mediated.

selective pressure contributing to the rise and distribution of resistant and pathogenic bacteria within the same aquatic environment ${ }^{[102]}$. Additionally, bacteria in the environments are able to produce antimicrobial compounds, thus making them capable of acquiring or expressing antimicrobial resistant genes to protect themselves from the toxicity of antibiotics present in the environments ${ }^{[103]}$. Therefore, the presences of aquatic bacterium may function as reservoirs for antibiotic resistance genes and plays a crucial role in the spread of antibiotic resistance in aquatic environments ${ }^{[101]}$.

Vibrio parahaemolyticus - both as a pathogenic strain carrying virulence genes (direct hemolysin $(t d h)$ and/or $t d h$ related hemolysin (trh) and as a MDR strain, is difficult to be controlled. Recently, there is a discovery on the ability of $V$. parahaemolyticus to withstand the bile salts, then utilize bile as signaling cue to launch its virulence ${ }^{[104]}$. The human bile in gastrointestinal system is known as the first defense mechanism against bacteria invasion in human. Bile salts in human not only aid during digestion of food but possess antimicrobial activities as they have the ability to inhibit the survival of bacteria in the human gastrointestinal tract. However, this usual defense is interrupted with the ability of $V$. parahaemolyticus to sense bile salts. The bacteria enters into the human gastrointestinal system, two major complex protein $\mathrm{Vtr} A$ and $\mathrm{VtrC}$ will interact and forms complex protein on host cell, binds with bile salts and triggers the cell to produce toxins. Upon binding of bile salts to the VtrA/VtrC complex, the cytoplasmic DNA binding domain of VtrA is activated which in turn induces VtrB to activate, resulting in the T3SS2 expression. T3SS2 virulence is secreted thus causing illness to human. This mode of mechanism ensures the survival of pathogenic $V$. parahaemolyticus in the environments and increase in the bacterial infections ${ }^{[104,105]}$. In addition, the T3SS2 is associated with $t d h$ - and/or trh-positive $V$. parahaemolyticus strains ${ }^{[106]}$. Hence, this information is significant to all healthcare personnel in order to know the mechanism of $V$. parahemolyticus infections and able to decide the best treatment for the infection.

\section{CONCLUSION}

$V$. parahaemolyticus infection is a predominant global health threat to both developed and developing countries. The pathogenesis of infection and symptoms are minor or self-limiting upon ingestion of unsafe food. However, the rising number of people falling ill with $V$. parahaemolyticus has constrained the socioeconomic and healthcare systems. There are various factors contributing for foodborne diseases to remain as a global public health challenge. Although many foodborne diseases have been controlled with proper management methods, new threats do continuously emerge. The changes among microorganism leads to the emergence of new pathogens, increased antibiotic resistant strains in the environment, and alteration in pathogen's virulence. In addition, people in many countries eat food prepared outside their homes which potentially exposing themselves to high risks of poor hygiene in retail food service surroundings. In many situations, foodborne diseases go unrecognized, underreported, unreported, or not investigated at all ${ }^{[107]}$. All these challenges involve a constant monitoring of foodborne pathogens and management food safety to ensure human wellbeing. 
Hence, adequate management of $V$. parahaemolyticus is required to control the widespread of this bacterium. Aquatic products are one of the main reservoirs for pathogenic and multidrug resistant $V$. parahaemolyticus. Therefore, there is an urgent prerequisite for the expansion of non-antibiotic technique to manage multidrug resistance (MDR) among pathogens due to declining efficacy of antibiotics and deficiency of new antibiotic in development pipeline ${ }^{[108-110]}$. Hence, further research can be done using bacteriophages and exploring the usefulness of it the management of $V$. parahaemolyticus. Phages are approved and recognized by the US regulatory bodies as a potential bio-control agent to control and prevent pathogens including Vibrio $\mathrm{sp}^{[111-117]}$. In addition, it can be utilized in the agriculture and aquaculture industries instead of antibiotics to control bacterial infections that occur in the farms. This will sooner or later reduce the dependency towards antibiotics that leads to resistant genes profile in the environment ${ }^{[118]}$.

In addition, the antibiotic resistance mediation of $V$. parahaemolyticus could be detected by plasmid curing assay (Figure 2). This fast, reliable and inexpensive method uses curing agent to eliminate bacteria plasmids and determine antibiotic resistance mediation. Mostly food safety studies involve a huge number of sample thus hindering the use of costly NGS. Hence, many researchers have utilized and reported the use of plasmid curing assay to determine antibiotic resistance mediation among environmental isolates $^{[119-124]}$. The results from this curing assay may influence an effective antibiotic management policy in the aquaculture sector. With this valuable knowledge, farmers could alternate the antibiotics used in their farms occasionally which will allow the bacteria to lose its resistance to a specific antibiotic ${ }^{[11,12]}$. Furthermore, the study of $V$. parahaemolyticus genome could provide vital information on the particular strain and further strengthen the management strategies $^{[125,126]}$. In summary, the public should be given adequate information on $V$. parahaemolyticus thru awareness campaigns in order to ensure food safety thru out the whole food industry from production to consumption ${ }^{[127]}$.

\section{AUTHORS CONTRIBUTION}

The literature review and manuscript writing were performed by VL and K-YL. JW-FL, N-SAM, SHW, B-HG and L-HL provided vital guidance and support as content expert and proofread of the writing. L-HL and VL founded the research project.

\section{CONFLICT OF INTEREST}

The authors declare that the research was conducted in the absence of any commercial or financial relationships that could be construed as a potential conflict of interest.

\section{ACKNOWLEDGEMENTS}

This work was supported by PVC Award Grant (Project No. PVC-ECR-2016), External Industry Grant (Biotek Abadi - Vote No. GBA-808138 and GBA-808813) awarded to L-HL.

\section{REFERENCE}

1. World Health Organization. WHO estimates of the global burden of foodborne diseases. Foodborne diseases burden epidemiology reference group 2007-2015. 2015. Accessed on 4 July 2019; Available from: http://www.who.int/foodsafety/publications/foodborne_disease/ fergreport/en/.

2. Fund F, Wang HS, Menon S. Food safety in the $21^{\text {st }}$ century. Biomed J 2018; 41: 88-95.

3. World Health Organization. Food Safety Fact sheet no. 399. 2015 Accessed on 4 July 2019; Available from: http://www.who.int/mediacentre/factsheets/fs399/en/.

4. Khoo CH, Cheah YK, Lee LH, et al. Virulotyping of Salmonella enterica subsp. enterica isolated from indigenous vegetables and poultry meat in Malaysia using multiplex-PCR. Antonie van Leeuwenhoek 2009; 96(4): 441-457.

5. Cheah YK, Learn-Han L, Noorzaleha AS, et al. Characterization of multiple-antimicrobial-resistant Salmonella enterica subsp. enterica isolated from indigenous vegetables and poultry in Malaysia. Let App Microbiol 2008a; 46(3): 318-324.

6. Cheah YK, Salleh NA, Lee LH, et al. Comparison of PCR fingerprinting techniques for the discrimination of Salmonella enterica subsp. enterica serovar Weltevreden isolated from indigenous vegetables in Malaysia. World J Microbiol Biotech 2008; 24(3): 327-335.

7. Learn-Han L, Cheah YK, Salleh NA, et al. Analysis of Salmonella Agona and Salmonella Weltevreden in Malaysia by PCR fingerprinting and antibiotic resistance profiling. Antonie Van Leeuwenhoek 2008; 94(3): 377-387.

8. Learn-Han L, Cheah YK, Shiran MS, et al. Molecular characterization and antimicrobial resistance profiling of Salmonella enterica subsp. enterica isolated from 'Selom' (Oenanthe stolonifera). Inter Food Res J 2009; 16(1): 191-202.

9. Eng SK, Pusparajah P, Ab Mutalib NS, et al. Salmonella: a review on pathogenesis, epidemiology and antibiotic resistance. Front Life Sci 2015; 8(3): 284-293.

10. Letchumanan V, Chan KG, Lee LH. Vibrio parahaemolyticus: A review on the pathogenesis, prevalence and advance molecular identification techniques. Front Microbiol 2014; 5: 1-13.

11. Letchumanan V, Yin WF, Lee LH, et al. Prevalence and antimicrobial susceptibility of Vibrio parahaemolyticus isolated from retail shrimps in Malaysia. Front Microbiol 2015a; 6: 1-11.

12. Letchumanan V, Pusparajah P, Tan LT-H, et al. Occurrence and Antibiotic resistance of Vibrio parahaemolyticus from shellfish in Selangor, Malaysia. Front Microbiol 2015b; 6: 1-11.

13. Law JWF, Letchumanan V, Chan KG, et al. Insights into detection and identification of foodborne pathogens. Edited by Om V. Singh. Food Borne Pathogens and Antibiotic Resistance. WILEY Blackwell 2016.

14. Heng SP, Letchumanan V, Deng CY, et al. Vibrio vulnificus: an environmental and clinical burden. Front Microbiol 2017; 8: 1-14.

15. Law JWF, Ab Mutalib NS, Chan KG, et al. An insight into the isolation, enumeration, and molecular detection of Listeria monocytogenes in food. Front Microbiol 2015a; 6: 1-15.

16. Law JWF, Ab Mutalib NS, Chan KG, et al. Rapid methods for the detection of foodborne bacterial pathogens: principles, applications, advantages and limitations. Front Microbiol 2015b; 5: 1-19.

17. Wang R, Zhong Y, Gu X, et al. The pathogenesis, detection, and prevention of Vibrio parahaemolyticus. Front Microbiol 2015; 6: 1-13.

18. Baker-Austin C, Trinanes J, Gonzalez-Escalona N \& MartinezUrtaza, J. Non-Cholera vibrios: the microbial barometer of climate change. Trends Microbiol. 25, 76-84 (2017).

19. Abd-Elghany SM, Sallam KI. Occurrence and molecular identification of Vibrio parahaemolyticus in retail shellfish in Mansoura, Egypt. Food Cont 2013; 33: 399-405.

20. Scallan E, Hoekstra RM, Angulo FJ, et al. Foodborne illness acquired in the United States-Major pathogens. Emerg Infect Dis 2011; 17: $7-15$.

21. Huang JY, Henao OL, Griffin PM, et al. Infection with pathogens transmitted commonly through food and the effect of increasing use of culture-independent diagnostic tests on surveillance - Foodborne diseases active surveillance network, 10 U.S. sites, 2012-2015. Morbidity and Mortality Weekly Report (MMWR) 2016; 65: 368-371.

22. Zhang L, Orth K. Virulence determinants for Vibrio parahaemolyticus infection. Curr Opin Microbiol 2013; 16: 70-77.

23. Daniel R, Yoo J, Fratamico R, et al. Two Cases of Vibrio Infection and Sepsis in the Delaware Estuary. The Medicine Forum 2016; 17: 1-2.

24. Thompson FL, Iida T, Swings J. Biodiversity of Vibrios. Microbiol Mol. Biol Rev. 2004; 68: 403-431.

25. Lippi D, Gotuzzo E. The greatest steps towards the discovery of Vibrio cholerae. Clin Microbiol Infect 2014; 20: 191-195.

26. Sawabe T, Ogura Y, Matsumura Y, et al. Updating the Vibrio clades defined by multilocus sequence phylogeny: proposal of eight new clades, and the description of Vibrio tritonius sp. nov. Front Microbiol 2013; 4: 414-424.

27. Austin B. Vibrios as causal agents of zoonoses. Veterinary Microbiol 2010; 140: 310-317.

28. Batz MB, Hoffmann S, Morris Jr JG. Ranking the disease burden of 14 pathogens in food sources in the United States using attribution data from outbreak investigations and expert elicitation. J Food Protect 2012; 75(7): 1278-1291.

29. Fujino T, Okuno Y, Nakada D, et al. On the bacteriological examination of shirasu food poisoning. Medic J Osaka University 1953; 4: 299-304.

30. Shinoda S. Sixty years from the discovery of Vibrio parahaemolyti- 
cus and some recollections. Biocontrol Sci 2011; 16: 129-137.

31. Odeyemi OA, Stratev D. Occurrence of antimicrobial resistant or pathogenic Vibrio parahaemolyticus in seafood. A mini review. Revue de Médecine Vétérinaire 2016; 67: 93-98.

32. Su YC, Liu C. Vibrio parahaemolyticus: A concern of seafood safety. Food Microbiology 2007; 24(6): 549-558.

33. Aberoumand AU. Occurrence and pathogenic vibrios in the marine environment of potentially pathogenic the straits of Messina, Italy. World J Fish Mar Sci 2010; 3: 376-382.

34. Kubota K, Kasuga F, Iwasaki E, et al. Estimating the burden of acute gastroenteritis and foodborne illness caused by Campylobacter, Salmonella, and Vibrio parahaemolyticus by using population-based telephone survey data, Miyagi Prefecture, Japan, 2005 to 2006. J Food Protect 2011 74: $1592-1598$.

35. Hara-Kudo Y, Sugiyama K, Nishibuchi M, et al. Prevalence of pandemic thermostable direct hemolysin-producing Vibrio parahaemolyticus $\mathrm{O} 3: \mathrm{K} 6$ in seafood and the coastal environment in Japan. App Environ Microbiol 2003; 69: 3883-3891.

36. Hara-Kudo Y, Saito S, Ohtsuka K, et al. Characteristics of a sharp decrease in Vibrio parahaemolyticus infections and seafood contamination in Japan. Intern J Food Microbiol 2012; 157(1): 95-101.

37. Yu WT, Jong KJ, Lin YR, et al. Prevalence of Vibrio parahaemolyticus in oyster and clam culturing environments in Taiwan. Intern J Food Microbiol 2013; 160: 185-192.

38. Li YH, Xie X, Shi X, et al. Vibrio parahaemolyticus, Southern coastal region of China, 2007-2012. Emerg Infect Dis 2014; 20(4): 685-688.

39. Bhuiyan NA, Ansaruzzaman M, Kamruzzaman M, et al. Prevalence of the pandemic genotype of Vibrio parahaemolyticus in Dhaka, Bangladesh, and significance of its distribution across different serotypes. J Clin Microbiol 2002; 40: 284-286.

40. Alam MJ, Tomochika KI, Miyoshi SI, et al. Environmental investigation of potentially pathogenic Vibrio parahaemolyticus in the Seto-Inland Sea, Japan. FEMS Microbiol Lett 2002; 208: 83-87.

41. Toyofuku H. Vibrio parahaemolyticus risk management in Japan. In G. Sauve (Ed.), Molluscan Shellfish Safety (pp. 129-136). New York, NY Springer. 2014.

42. Wu Y, Wen J, Ma Y, et al. Epidemiology of foodborne disease outbreaks caused by Vibrio parahaemolyticus, China, 2003-2008. Food Cont 2014; 46: 197-202.

43. Liu X, Chen Y, Wang X, et al. Foodborne disease outbreaks in China from 1992 to 2001 - National foodborne surveillance system. J Hyg Res 2004; 33: 725-727.

44. Wong HC, Liu SH, Wang TK, et al. Characterization of Vibrio parahae molyticus O3:K6 from Asia. App Environ Microbiol 2000b; 66: 39813986.

45. Matsumoto C, Okuda J, Ishibashi M, et al. Pandemic spread of an O3:K6 clone of Vibrio parahaemolyticus and emergence of related strains evidenced by arbitrarily primed PCR and toxRS sequence analyses. J Clin Microbiol 2000; 38: 578-585.

46. Vandy S, Leakhann S, Phalmony H, et al. Vibrio parahaemolyticus enteritis outbreak following a wedding banquet in a rural village - Kampun Speu, Cambodia. Western Pac Surveill Response J 2012; 3(4): 25-28

47. Thongjun J, Mittraparp-Arthorn P, Yingkajorn M, et al. The trend of Vibrio parahaemolyticus infection in Southern Thailand from 2006-2012. Trop Medic Intern Health 2013; 41(4): 151-156.

48. Yano Y, Hamano K, Satomi M, et al. Prevalence and antimicrobial susceptibility of Vibrio species related to food safety isolated from shrimp cultured at inland ponds in Thailand. Food Cont 2014; 38: 30-45.

49. Al-Othrubi SMY, Kqueen CY, HMirhosseini CY, et al. Antibiotic resistance of Vibrio parahaemolyticus isolated from cockles and shrimp se food marketed in Selangor, Malaysia. Clin Microbiol 2014; 3: 148-154.

50. Cann DC, Taylor LY, Merican Z. A study of the incidence of Vibrio parahaemolyticus in Malaysian shrimp undergoing processing for export. Epidemiol Infect 1981; 87(3): 485-491.

51. Bilung LM, Radu S, Bahaman AR, et al. Detection of Vibrio parahaemolyticus in cockle (Anadara granosa) by PCR. FEMS Microbiol Lett 2005; 252: 85-88.

52. Sujeewa AKW, Norrakiah AS, Laina M. Prevalence of toxic genes of Vibrio parahaemolyticus in shrimps (Penaeus monodon) and culture environment. Intern Food Res J 2009; 16: 89-95.

53. Noorlis A, Ghazali FM, Cheah YK, et al. Antibiotic resistance and biosafety of Vibrio cholerae and Vibrio parahaemolyticus from freshwate fish at retail level. Intern Food Res J 2011; 18(4): 1523-1530.

54. Sani NA, Ariyawansa S, Babji AS, et al. The risk assessment of Vibrio parahaemolyticus in cooked black tiger shrimps (Penaeus monodon) in Malaysia. Food Cont 2013; 31(2): 546-552.

55. Paydar M, Teh CSJ, Thong KL. Prevalence and characterization of potentially virulent Vibrio parahaemolyticus in seafood in Malaysia usin conventional methods, PCR and REP-PCR. Food Cont 2013; 32: 13-18.

56. Nakaguchi Y. Contamination by Vibrio parahaemolyticus and its virulen strains in seafood marketed in Thailand, Vietnam, Malaysia, and Indonesia. Trop Medic Health 2013; 41: 95-102.

57. Wong HC, Liu SH, Ku LW, et al. Characterization of Vibrio parahaemolyticus isolates obtained from foodborne illness outbreaks during 1992 through 1995 in Taiwan. J Food Protect 2000a; 63(7): 900-906.

58. Lee WC, Lee MJ, Kim JS, et al. Foodborne illness outbreaks in Korea and Japan studied retrospectively. J Food Protect 2001; 64: 899-902.

59. Dileep V, Kumar HS, Kumar Y, et al. Application of polymerase chain reaction for detection of Vibrio parahaemolyticus associated with tropical seafood and coastal environment. Lett App Microbiol 2003; 36: 423-427.

60. Nordstrom JL, Vickery MC, Blackstone GM, et al. Development of a multiplex real-time PCR assay with an internal amplification control for the detection of total and pathogenic Vibrio parahaemolyticus bacteria in oysters. App Environ Microbiol 2007; 73: 5840-5847.

61. Sahilah AM, Laila RA, Sallehuddin HM, et al. Antibiotic resistance and molecular typing among cockle (Anadara granosa) strains of Vibrio parahaemolyticus by polymerase chain reaction (PCR)-based analysis. World J Microbiol Biotech 2014; 30: 649-659.

62. Tanil GB, Radu S, Nishibuchi M, et al. Characterization of Vibrio parahaemolyticus isolated from coastal seawater in peninsular Malaysia. Southeast Asian J Trop Med Public Health 2005; 36(4): 940948.

63. Elexson N, Afsah-Hejri L, Rukayadi Y, et al. Effect of detergents as antibacterial agents on biofilm of antibiotics-resistant Vibrio parahaemolyticus isolates. Food Cont 2014; 35: 378-385.

64. Lee LH, Ab Mutalib NS, Law JW, et al. Discovery on antibiotic resistance patterns of Vibrio parahaemolyticus in Selangor reveals carbapenemase producing Vibrio parahaemolyticus in marine and freshwater fish. Front Microbiol 2018; 9: 2513

65. Lee LH, Raghunath P. Vibrionaceae diversity, multidrug resistance and management. Front Microbiol 2018; 9: 563.

66. Tan CW, Malcolm TTH, Kuan CH, et al. Prevalence and antimicrobial susceptibility of Vibrio parahaemolyticus isolated from short mackerels (Rastrelliger brachysoma) in Malaysia. Front Microbiol 2017; 8: 1-9.

67. Sudha S, Mridula C, Silvester R, et al. Prevalence and antibiotic resistance of pathogenic Vibrios in shellfishes from Cochin market. Indian J Mar Sci 2014; 43: 815-824.

68. Ceccarelli D, Hasan NA, Hug A, et al. Distribution and dynamics of epidemic and pandemic Vibrio parahaemolyticus virulence factors. Front Cell Infect Microbiol 2013; 3: 1-9.

69. Ramamurthy T, Nair GB. Bacteria: Vibrio parahaemolyticus. Encyclopedia of Food Safety, 2014; 1: 555-563

70. Pazhani GP, Bhowmik SK, Ghosh S, et al. Trends in the epidemiology of pandemic and non-pandemic strains of Vibrio parahaemolyticus isolated from diarrheal patients in Kolkata, India. PLoS Neglected Trop Dis 2014; 8: 2815-2825.

71. Kanungo S, Sur D, Ali M, et al. Clinical, epidemiological, and spatial characteristics of Vibrio parahaemolyticus diarrhea and cholera in the urban slums of Kolkata, India. BMC Pub Health 2012; 12: 830-840.

72. Reyhanath PV, Kutty R. Incidence of multidrug resistant Vibrio parahaemolyticus isolated from Ponnani, India. Iranian J Microbiol 2014; 6: 60-67.

73. Okuda J, Ishibashi M, Hayakawa E, et al. Emergence of a unique $\mathrm{O} 3 \cdot \mathrm{K} 6$ clone of Vibrio parahaemolyticus in Calcutta, India and isolation of strains from the same clonal group from Southeast Asian travelers arriving in Japan. J Clin Microbiol 1997; 35: 3150-3155.

74. Miwatani T, Takeda Y. (Eds.). Vibrio parahaemolyticus: A causative bacterium of food poisoning. Tokyo: Saikon. 1976.

75. Aldova E, Zakhariev ZA, Dinev TS, et al. Vibrio parahaemolyticus in the Black Sea. Zentralbl Bakteriol B 1971; 218(2): 176-88.

76. Papa F. Study and significance of Vibrio parahaemolyticus in the coastal waters of Guadeloupe. Bull Soc Pathol Exot Filiales 1980; 73: 380-383.

77. Qadri F, Chowdhury NR, Takeda Y, et al. Vibrio parahaemolyticus Seafood safety and associations with higher organisms. In S. Belkin \& R. R. Colwell (Eds.), Oceans and Health: Pathogens in the Marine Environment (pp. 277-295). New York, NY: Springer 2005.

78. Serracca L, Battistini R, Rossini I, et al. Vibrio virulence genes in fishes collected from estuarine waters in Italy. Lett App Microbiol 2011; 53(4): 403-408.

79. Molero X, Bartolome' RM, Vinuesa T, et al. Acute gastroenteritis due to Vibrio parahaemolyticus in Spain: presentation of 8 cases. Med Clin (Barc) 1989: 92:1-4.

80. Robert-Pillot A, Guenole A, Lesne J, et al. Occurrence of the $t d h$ and trh genes in Vibrio parahaemolyticus isolates from waters and raw shellfish collected in two French coastal areas and from seafood imported into France. Intern J Food Microbiol 2004; 91: 319-325.

81. Lozano-Leon A, Torres J, Osorio CR, et al. Identification of $t d h$ positive Vibrio parahaemolyticus from an outbreak associated with raw oyster consumption in Spain. FEMS Microbiol Lett 2003; 226: 281-284.

82. Martinez-Urtaza J, Simental L, Velasco D, et al. Pandemic Vibrio parahaemolyticus O3:K6, Europe. Emerg Infect Dis $J$ 2005; 11 : 1319-1320.

83. Wagley S, Koofhethile K, Wing JB, et al. Comparison of $V$. parahaemolyticus isolated from seafoods and cases of gastrointestinal disease in the UK. Intern J Environ Health Res 2008; 18(4): 283-293.

84. Ottaviani D, Leoni F, Rocchegiani E, et al. First clinical report of pandemic Vibrio parahaemolyticus O3:K6 infection in Italy. J Clin Microbiol 2008; 46: 2144-2145.

85. Ottaviani D, Leoni F, Roccehegiani E, et al. Prevalence, serotyping and molecular characterization of Vibrio parahaemolyticus in mussels from Italian growing areas, Adriatic Sea. Environ Microbiol Rep 2010; 2(1): 92-197.

86. Molenda JR, Johnson WG, Fishbein M, et al. Vibrio parahaemolyticus gastroenteritis in Maryland: Laboratory aspects. App Microbiol 1972; 24: 444-448

87. Daniels NA, MacKinnon L, Bishop R, et al. Vibrio parahaemolyticu. infection in the United States, 1973-1998. J Infect Dis 2000; 181: 1661-1666.

88. Centres for Disease Control and Prevention (CDC). Outbreak of Vibrio parahaemolyticus infection associated with eating raw oysters and clams harvested from Long Island Sound-Connecticut, New Jersey and New York, 1998. Morb Mortal Wkly Rep 1999; 48: 48-51.

89. McLaughlin JB, DePaola A, Bopp CA, et al. Outbreak of Vibrio parahaemolyticus gastroenteritis associated with Alaskan oysters. New Eng J Medic 2005;353(14): 1463-1470.

90. DePaola A, Kaysner CA, Bowers J, et al. Environmental investigations of Vibrio parahaemolyticus in oysters after outbreaks in Washington, Texas, and New York (1997 and 1998). App Environ Microbiol 2000; 66: 4649-4654 
91. Newton A, Kendall M, Vugia DJ, et al. Increasing rates of vibriosis in the United States, 1996-2010: Review of surveillance data from 2 systems. Clin Infect Dis 2012; 54: 391-395.

92. Centers for Disease Control and Prevention (CDC). Vibrio parahaemolyticus Infections associated with consumption of raw shelfish at three states, 2006. Morb Mort Wkly Rep 2006; 55: 1-2.

93. Alanis AJ. Resistance to antibiotics: are we in the post-antibiotic era? Arch Med Res 2005; 36: 697-705.

94. Zhang R, Pan L, Zhao Z. High incidence of plasmids in marine Vibrio species isolated from Mai Po Nature Reserve of Hong Kong. Ecotoxicology 2012; 21: 1661-1668.

95. Letchumanan V, Ab Mutalib NS, Wong SH, et al. Determination of antibiotic resistance patterns of Vibrio parahaemolyticus from shrimp and shellfish in Selangor, Malaysia. Prog Microbes Mol Biol; 2019;1(1).

96. Kim M, Kwon TH, Jung SM, et al. Antibiotic resistance of bacteria isolated from the internal organs of edible snow crabs. PLoS ONE 2013; 8: $1-10$.

97. Shrestha UT, Adhikari N, Maharjan R, et al. Multidrug resistant Vibrio cholerae 01 from clinical and environmental samples in Kathmandu city. BMC Infect 2015; 15: 1-7.

98. Khan WA, Saha D, Ahmed S, et al. Efficacy of ciprofloxacin for treatment of cholera associated with diminished susceptibility to ciprofloxacin to Vibrio cholerae O1. PloS ONE 2015; 10: 1-11.

99. Martinez JL. Recent advances on antibiotic resistance genes. In M. Fingerman \& R. Nagabhushanam (Eds.), Recent Advances in Marine Biotechnology (pp. 13-32). Boca Raton: CRC Press. 2003.

100. Marti E, Variatza E, Balcazar JL. The role of aquatic ecosystems as reservoirs of antibiotic resistance. Trends Microbiol 2014; 22(1): 36-41.

101. Cabello FC. Heavy use of prophylactic antibiotics in aquaculture: A growing problem for human and animal health and for the environment. Environ Microbiol 2006; 8: 397-414

102. Baquero F, Martinez JL, Canton R. Antibiotics and antibiotic resistance in water environments. Curr Opin Biotechnol 2008; 19: 260-265.

103. World Health Organization (WHO). Food Safety (Ed.). Switzerland: WHO. 2017.

104. Letchumanan V, Chan KG, Khan TM, et al. Bile Sensing: The activation of Vibrio parahaemolyticus virulence. Front Microbiol 2017; 8(728): 1-6.

105. Wang S, Zhang Z, Malakar PK, Pan Y, Zhao Y. The fate of bacteria in human digestive fluids: A new perspective into the pathogenesis of Vibrio parahaemolyticus. Frontiers in Microbiology. 2019;10:1614.

106. Raghunath P. Roles of thermostable direct hemolysin (TDH) and TDHrelated hemolysin (TRH) in Vibrio parahaemolyticus. Front Microbio 2015; 5: 1-4.

107. Rice LB. Federal funding for the study of antimicrobial resistance in nosocomial pathogens: No ESKAPE. J Infect Dis 2008; 197: 1079-1081.

108. Freire-Moran L, Aronsson B, Manz C, et al. Critical shortage of new antibiotics in development against multidrug-resistant bacteria - Time to react is now. Drug Resis Updates 2011; 14(2): 118-124.

109. Carlet J, Collignon P, Goldmann D, et al. Society's failure to protect a precious resource: Antibiotics. The Lancet 2011; 378(9788): 369-371.
110. Vinod MG, Shivu MM, Umesha KR, et al. Isolation of Vibrio harveyi bacteriophage with a potential for biocontrol of luminous vibriosis in hatchery environments. Aqua 2006; 255: 117-124.

111. Karunasagar I, Shivu MM, Girisha SK, et al. Biocontrol of pathogens in shrimp hatcheries using bacteriophages. Aqua 2007; 268: 288-292.

112. Bren L. Bacteria eating virus approved as food additive. FDA Consumer 2007; 41: 20-22.

113. Coffey B, Mills S, Coffey A, et al. Phage and their lysins as biocontrol agents for food safety applications. Annual Rev Food Sci Tech 2010; 1: 449-468.

114. Hagens S, Loessner M. Bacteriophage for biocontrol of foodborne pathogens: Calculations and considerations. Curr Pharm Biotech 2010; 11(1): 58-68.

115. Jassim SAA. Limoges, RG. Natural solution to antibiotic resistance: Bacteriophages - the living drugs. World J Microbiol Biotech 2014; 30: $2153-2170$

116. Golkar Z, Bagasra O, Pace DG. Bacteriophage therapy: A potential solution for the antibiotic resistance crisis. J Infect Develop Count 2014; 8(02): 129-136.

117. Letchumanan V, Chan KG, Pusparajah P, et al. Insights into bacteriophage application in controlling Vibrio species. Front Microbiol 2016; 7: 1114

118. Salisbury V, Hedges RW, Datta N. Two modes of 'curing' transmissible plasmids. J Gen Microbiol 1972; 70: 443-452.

119. Kamat AS. Nair, CKK. Evidence for plasmid-mediated toxin production in Bacillus cereus BIS-59. World J Microbiol Biotech 1992; 8: 210-211.

120. Barman S, Chatterjee S, Chowdhury G, et al. Plasmid-mediated streptomycin and sulfamethoxazole resistance in Shigella flexneri 3a. Inter J Antimicrob Agents 2010; 36: 348-351.

121. Reboucas RH, Viana de Sousa O, Sousa Lima A, et al. Antimicrobial resistance profile of Vibrio species isolated from marine shrimp farming environments (Litopenaeus vannamei) at Cear'a, Brazil. Environ Res 2011; 111: 21-24.

122. Carvalho FC, Sousa OV, Carvalho EM, et al. Antibiotic resistance of Salmonella spp. isolated from shrimp farming freshwater environment in Northeast region of Brazil. J Path 2013; 2013: 1-5.

123. Costa RA, Araujo RL, Souza OV, et al. Antibiotic-resistant Vibrios in farmed shrimp. BioMed Res Inter 2014; 2014: 2-5.

124. Letchumanan, V, Chan KG, Lee LH. An insight of traditional plasmid curing in Vibrio species. Front Microbiol 2015; 6: 735

125. Letchumanan, V, Ser HL, Chan KG, et al. Genome sequence of Vibrio parahaemolyticus VP103 strain isolated from shrimp in Malaysia. Front Microbiol 2016; 7: 1496.

126. Letchumanan, V, Ser HL, Tan WS, et al. Genome sequence of Vibrio parahaemolyticus VP152 strain isolated from Penaeus indicus in Malaysia. Front Microbiol 2016; 7: 1410.

127. Letchumanan $\mathrm{V}$, Wong $\mathrm{PC}$, Goh $\mathrm{BH}$, et al. A review on the characteristics, taxanomy and prevalence of Listeria monocytogenes. Prog Microbes Mol Biol 2018; 1(1) 